\title{
Short-term effects of subchronic low-level hydrogen sulfide exposure on oil field workers
}

\author{
Haider Abdul-Lateef Mousa
}

Received: 28 July 2014/ Accepted: 10 September 2014/Published online: 15 October 2014

(c) The Japanese Society for Hygiene 2014

\begin{abstract}
Objectives To investigate the short-term effects of lowlevel hydrogen sulfide $\left(\mathrm{H}_{2} \mathrm{~S}\right)$ exposure on oil field workers. Materials and methods Observational study included 34 patients who work at an oil field. All patients were males with age range of 22-60 years (mean 37 years). The data were collected by systematic questionnaire about symptoms. The inclusion criteria of patients were symptoms related to inhalation of $\mathrm{H}_{2} \mathrm{~S}$ gas in the oil field. The complaints should be frequent and relapsed after each gas exposure and disappeared when there was no gas exposure. Exclusion criteria were the symptoms which experienced with or without $\mathrm{H}_{2} \mathrm{~S}$ exposure. The presence of $\mathrm{H}_{2} \mathrm{~S}$ gas was confirmed by valid gas detector devices.

Results The most frequent presenting symptom was nasal bleeding. It was revealed in 18 patients $(52.9 \%)$. This followed by pharyngeal bleeding, gum bleeding, and bloody saliva (mouth bleeding) which were encountered in five cases for each complaint (14.7\%). Other less frequent presenting symptoms were tongue bleeding, bloody sputum, headache, abdominal colic, pharyngeal soreness, fatigue, and sleepiness.

Conclusions Nasal mucosa was the most vulnerable part to $\mathrm{H}_{2} \mathrm{~S}$ effect. Inhalation of $\mathrm{H}_{2} \mathrm{~S}$ produced upper respiratory tract epithelial damage that led to bleeding from nose, pharynx, gum, tongue, trachea, and bronchi. There were no complaints of asthmatic attack upon exposure to low level
\end{abstract}

H. A.-L. Mousa

College of Medicine, University of Basrah, Basrah, Iraq

H. A.-L. Mousa ( $\square)$

PO Box 601, Post code 42001 Ashar, Basrah, Iraq

e-mail: haideramousa@ hotmail.com; haideramousa@gmail.com of $\mathrm{H}_{2} \mathrm{~S}$. Sunlight had a significant role in reduction of ambient air $\mathrm{H}_{2} \mathrm{~S}$ level.

Keywords Hydrogen sulfide $\cdot \mathrm{H}_{2} \mathrm{~S}$ health effects $\cdot$ Oil fields $\mathrm{H}_{2} \mathrm{~S} \cdot$ Oil fields occupational hazards $\cdot \mathrm{H}_{2} \mathrm{~S}$ respiratory symptoms $\cdot \mathrm{H}_{2} \mathrm{~S}$ toxicity $\cdot$ Upper respiratory bleeding

\section{Introduction}

Hydrogen sulfide $\left(\mathrm{H}_{2} \mathrm{~S}\right)$ is a toxic gas with a characteristic rotten egg odor. It is a by-product of numerous industrial processes, including sewage treatment, pulp and paper processing, petroleum and natural gas drilling and refining operations, and rayon textile manufacturing.

Human exposure to the toxic effects of $\mathrm{H}_{2} \mathrm{~S}$ is characteristically dose related and most notably involves the nervous, cardiovascular, and respiratory systems [1]. It was reported that exposure to higher $\mathrm{H}_{2} \mathrm{~S}$ concentration caused severe neurotoxicity, status epilepticus, bronchospasms, and delayed respiratory failure [2]. Following inhalation, $\mathrm{H}_{2} \mathrm{~S}$ dissociates into free sulfide and hydrogen ions in the blood circulation. Sulfide binds to many macromolecules, including cytochrome oxidase thereby preventing oxidative phosphorylation. This causes reversible inhibition of aerobic metabolism leading to cellular anoxia [3]. Olfactory deficits (hyposmia) with both a delayed and immediate onset have also been documented following repeated exposures to sublethal doses of $\mathrm{H}_{2} \mathrm{~S}$ in workers at a refinery construction site [4]. $\mathrm{H}_{2} \mathrm{~S}$ odor was strongly associated with reports of alteration of daily activities, negative mood states, mucosal irritation, and upper respiratory symptoms [5]. It was also concluded by experiment on rats that inhalation of $\mathrm{H}_{2} \mathrm{~S}$ had a severe cytotoxic effect on the nasal 
epithelium and a severe edematogenic effect on lung parenchyma [6] whereas acute exposure to $400 \mathrm{ppm} \mathrm{H}_{2} \mathrm{~S}$ induced severe mitochondrial swelling in support cells and olfactory neurons, which progressed to olfactory epithelial necrosis and sloughing [7]. On the other hand, subchronic

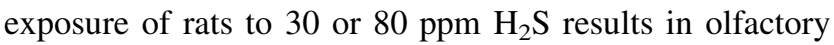
neuron loss and basal cell hyperplasia [1]. The lethal effect of acute exposure to $\mathrm{H}_{2} \mathrm{~S}$ is at persistent high concentrations (>500 ppm) [8]. Acute exposure to $\mathrm{H}_{2} \mathrm{~S}$ causes four dose-dependent human responses: hyperpnea, unconsciousness, apnea, and death [9]. Acute exposure to 50-100 ppm $\mathrm{H}_{2} \mathrm{~S}$ leads to neurological disorders (dizziness, headaches, loss of balance, lack of concentration, recent and long-term memory loss, mood unstableness, irritability, exhilaration, and sleep disturbances), behavior changes (anger, depression, tension, confusion, fatigue, and vigor), respiratory symptoms (apnea, cough, noncardiogenic pulmonary edema, and cyanosis), cardiovascular abnormalities (irregular heart beat or hypotension), eye irritations (conjunctivitis, lacrimation, and photophobia), skin symptoms (itching, dryness, and redness), and general deficits (nausea, libido decrease, gastrointestinal tract upsets, and loss of appetite) [10].

It is well known that acute exposure to high concentration of $\mathrm{H}_{2} \mathrm{~S}$ has immediate toxic or lethal sequelae whereas chronic exposure to lower concentration leads to different types of illnesses. There were few human or animal studies in regard to short-term subchronic health disorders of low $\mathrm{H}_{2} \mathrm{~S}$ level especially on the upper respiratory airways. Effect of sunlight on the ambient air $\mathrm{H}_{2} \mathrm{~S}$ level was also considered in the present study. The aim of the present study is to investigate the short-term effects of low-level $\mathrm{H}_{2} \mathrm{~S}$ exposure on oil field workers.

\section{Patients and methods}

An observational study was conducted including 34 patients who attended oil field clinic at Oil Company. They were complaining from symptoms related to $\mathrm{H}_{2} \mathrm{~S}$ exposure. The study was carried out between February 2012 and December 2013. It was exempted from ethical approval. The patients were oil field employee. Their ages were 22-60 years (mean 37 years). All were males. The study was performed at four oil field camps. One oil field was exposed to intermittent, fluctuating low concentration of $\mathrm{H}_{2} \mathrm{~S}$ in which workers regarded as case study group, whereas the other three oil fields were exposed to little or no $\mathrm{H}_{2} \mathrm{~S}$ gas in which workers regarded as control group. About 400-800 workers were available at each oil field. Their duties were administrative, maintenance, oil station operators, engineering, drilling, and service sectors. Oilseparation station (the units which separate crude oil from water) operators were the most likely people vulnerable to highest level of $\mathrm{H}_{2} \mathrm{~S}$ (up to $50 \mathrm{ppm}$ ). In the field with high $\mathrm{H}_{2} \mathrm{~S}$ level, the natural consistency of the crude oil contains high concentration of $\mathrm{H}_{2} \mathrm{~S}$ where the camp was built in between oil wells and oil-separation stations. All cases were reported in the field with high $\mathrm{H}_{2} \mathrm{~S}$ level. In the other three oil fields, there were no complaints related to gas effects. $\mathrm{H}_{2} \mathrm{~S}$ concentration was measured in the oil fields at several sites (oil-separation stations, workshops, living accommodation, and remote working areas with suspected high $\mathrm{H}_{2} \mathrm{~S}$ level). The $\mathrm{H}_{2} \mathrm{~S}$ gas was measured by fixed gas detectors, which are continuous monitoring devices, from which daily peak concentrations were recorded. Portable gas detectors were also used especially for tasks at remote areas. Dräger gas detectors were employed in the oil fields. Dräger portable gas detectors can be used to detect and measure more than 400 gases including combustible gases or vapors, toxic gases and also monitoring for low oxygen levels. These gas detectors which can be used for personal monitoring, area monitoring, confined space entry clearance measurements and gas leak detection. All work places and living accommodation have alarming system to alert employee when the $\mathrm{H}_{2} \mathrm{~S}$ concentration approaches a dangerous level. The $\mathrm{H}_{2} \mathrm{~S}$ sources were extinguished gas flares, crude oil-separation stations, leaking oil wells, and waste water. The latter was separated from crude oil in the separation stations and dumped out into opened reservoirs in the desert.

The inclusion criteria of patients were complaints which were related to inhalation of $\mathrm{H}_{2} \mathrm{~S}$ in the oil field at their living accommodation or at work place. The included cases were exposed to subchronic 4-50 ppm $\mathrm{H}_{2} \mathrm{~S}$ for few hours to few days whereas complaints of acute exposure to high $\mathrm{H}_{2} \mathrm{~S}$ concentration for brief period or complaints of chronic exposure for several months or years were excluded. The data were collected from patients who were seeking medical treatment about symptoms resulting from $\mathrm{H}_{2} \mathrm{~S}$ exposure. Systematic questionnaires were used to differentiate between complaints which were related or unrelated to $\mathrm{H}_{2} \mathrm{~S}$ gas. The following question items were applied: Is your symptom experienced after $\mathrm{H}_{2} \mathrm{~S}$ gas exposure? Is it recurring on each gas exposure? Is it disappearing when there is no gas odor? Is it correlated with potency of gas odor? Do you experience same symptom or free of symptom at your home residency outside the oil field? Do you have the same symptom before you have been employed in the oil field? Therefore, the symptoms should be frequent and recur at least twice after each gas exposure and disappear when there is no gas exposure. Exclusion criteria were whenever same symptoms experienced while the patient at home (outside oil field) or at work site. However, two patients whose symptoms were experienced at home, but exaggerated at work place after $\mathrm{H}_{2} \mathrm{~S}$ exposure were included. 
Table 1 The symptoms and associated illnesses in 34 patients complaining from $\mathrm{H}_{2} \mathrm{~S}$ effects

\begin{tabular}{|c|c|c|}
\hline Symptoms & No. of cases $(\%)$ & Associated illnesses (no.) and remarks \\
\hline Nasal bleeding & $14(41.2)$ & $\begin{array}{l}\text { Chronic sinusitis (1), nasal soreness (1), common cold (1), } \\
\text { rhinitis (1) }\end{array}$ \\
\hline Pharyngeal bleeding & $5(14.7)$ & Mild and less frequent bleeding at home (1) \\
\hline Gum bleeding & $3(8.8)$ & Gingivitis (1) \\
\hline Bloody saliva (mouth bleeding) & $4(11.8)$ & Mild and less frequent bleeding at home (1) \\
\hline Tongue bleeding & $1(2.9)$ & \\
\hline Nasal and tongue bleeding & $1(2.9)$ & Atrophic rhinitis \\
\hline Nasal bleeding and bloody sputum & $1(2.9)$ & Acute bronchitis and common cold \\
\hline Gum bleeding and bloody saliva & $1(2.9)$ & \\
\hline Nasal and gum bleeding & $1(2.9)$ & \\
\hline Nasal bleeding, headache, and abdominal colic & $1(2.9)$ & \\
\hline Pharyngeal soreness & $1(2.9)$ & Complaining at oil field only \\
\hline Headache, fatigue, and sleepiness & $1(2.9)$ & Complaining at oil field only \\
\hline
\end{tabular}

Specific symptoms of certain illnesses which were unrelated to gas inhalation were also excluded. These involved upper respiratory acute or chronic illnesses such as flu, pneumonia, chronic gum disease, bronchiectasis, or chronic obstructive airway disease.

There were 168 patients excluded from the study because their symptoms did not coincide with study criteria. Although they believed that their symptoms were related to $\mathrm{H}_{2} \mathrm{~S}$ inhalation. Most notably, the encountered symptoms were headache, eyes irritation, throat irritation, nasal blockage, weight loss, reduce sense of smell, sleep disturbances and sudden wake up with chest tightness, and difficulty of breathing for brief period. Reduced sense of smell might be the effect of chronic $\mathrm{H}_{2} \mathrm{~S}$ exposure which is outside the scope of the present study. It is worth to mention that most of oil field workers who complained from gas effects did not consult a physician because they used to experience the symptoms for long time. On the other hand, many people might not get symptoms from such exposure which could be explained by their native resistant to $\mathrm{H}_{2} \mathrm{~S}$ effects.

\section{Results}

Thirty-four patients were investigated whose symptoms were agreed with the inclusion criteria of the present study. Hydrogen sulfide was intermittently affecting oil field workers. In each time of gas spreading through the oil field camp, the duration of patients' inhalation of $\mathrm{H}_{2} \mathrm{~S}$ usually ranged from 8 to $12 \mathrm{~h}$ and rarely for few days. However, the cycles of $\mathrm{H}_{2} \mathrm{~S}$ exposure were repeated irregularly on daily bases or within every few days. $\mathrm{H}_{2} \mathrm{~S}$ bouts were intermittent with fluctuating concentrations because it was related to natural factors such as wind direction or speed, ambient temperature (highest $\mathrm{H}_{2} \mathrm{~S}$ level during winter season/lesser UV light intensity), day or night time, location of the worker within the camp, extinguished or non-extinguished gas flares, level of ventilation, and quantity of gas emission from its sources. $\mathrm{H}_{2} \mathrm{~S}$ concentration was ranged from 4 to $50 \mathrm{ppm}$ during the period of ambient gas existence whereas 0 ppm was recorded during gas absence and in the other three oil field locations. There was no other abnormal high concentration of poisonous gases detected other than $\mathrm{H}_{2} \mathrm{~S}$. On daily bases monitoring, the highest $\mathrm{H}_{2} \mathrm{~S}$ level was observed at night especially before sunrise, while at midday it almost always disappeared except in places nearby its sources. The dominant range of $\mathrm{H}_{2} \mathrm{~S}$ level during the days of gas existence was 8-50 ppm before sunrise and 0-2 ppm at midday time. After sunrise, there was gradual reduction in level of $\mathrm{H}_{2} \mathrm{~S}$. This might be the effect of sunlight (UV light) that dispenses or destroys the gas. The peak level (50 ppm) was recorded in the vicinity of oil-separation stations.

The symptoms of $\mathrm{H}_{2} \mathrm{~S}$ exposure were bleeding from nose, pharynx, gum, mouth, and tongue. Other patients also presented with bloody sputum, bloody saliva, headache, abdominal colic, pharyngeal soreness, fatigue, and sleepiness. The most common presenting complaint was nasal bleeding. It was observed in 18 patients $(52.9 \%)$, of which 14 cases $(41.2 \%)$ presented with nasal bleeding alone whereas four cases had additional symptoms related to $\mathrm{H}_{2} \mathrm{~S}$ exposure. This was followed by pharyngeal bleeding (five cases, $14.7 \%$ ), gum bleeding (five cases, $14.7 \%$ ), and bloody saliva which is unrecognized site of origin of mouth bleeding (five cases, $14.7 \%$ ) as shown in Table 1. All categories of bleeding were intermittent which observed after $\mathrm{H}_{2} \mathrm{~S}$ exposure. It was unassociated with pain or abnormal clinical features except those mentioned in 
Table 1, which included chronic sinusitis, nasal soreness, common cold, rhinitis, gingivitis, atrophic rhinitis, and acute bronchitis. The other less frequent symptoms were tongue bleeding, bloody sputum, headache, abdominal colic, pharyngeal soreness, fatigue, and sleepiness. The headache resulting from $\mathrm{H}_{2} \mathrm{~S}$ exposure was not responding to analgesics. Two patients had similar complaints at home and at oil field (pharyngeal bleeding and bloody saliva), though the symptoms were mild and less frequent at home than those experienced at the oil field. The features of bleeding resulting from $\mathrm{H}_{2} \mathrm{~S}$ were somewhat different from ordinary bleeding. It was usually rusty color, mixed homogenously with nasal discharge or with saliva or sputum. It was not flowing or dripping. The site of bleeding was diffuse and cannot pin point the site of origin on clinical examination. It was noticed by performing certain maneuver such as mouth gargle with water, expulsion of sputum, or nose blowing.

No serious $\mathrm{H}_{2} \mathrm{~S}$ poisoning (fatal cases, respiratory failure, or severe neurotoxicity) was reported because the $\mathrm{H}_{2} \mathrm{~S}$ was diffused on large surface area with low concentration. There were also no patients complained from bronchial asthmatic attack or exaggeration of bronchial asthma upon exposure to $\mathrm{H}_{2} \mathrm{~S}$. All patients were given non-specific conservative treatment such as antibiotics, mouthwash, vitamin $\mathrm{C}$, multivitamin, or normal saline nasal drops.

\section{Discussion}

The predominant complaint from short-term/low-concentration $\mathrm{H}_{2} \mathrm{~S}$ exposure in the present study was upper respiratory tract bleeding. The previous experimental studies on rats and human revealed a role of $\mathrm{H}_{2} \mathrm{~S}$ on the living cells. A study on experimental rats, $\mathrm{H}_{2} \mathrm{~S}$ inhalation was found to have a severe cytotoxic effect on the nasal epithelium [6] and olfactory epithelial necrosis and sloughing [7]. In human studies, $\mathrm{H}_{2} \mathrm{~S}$ was also found to have a dose-dependent intensification of cell death via apoptosis and necrosis [11]. The intracellular acidification of nasal epithelial cells by high-dose $\mathrm{H}_{2} \mathrm{~S}$ exposure and the inhibition of cytochrome oxidase at much lower $\mathrm{H}_{2} \mathrm{~S}$ concentrations suggest that changes in intracellular $\mathrm{pH}$ play a secondary role in $\mathrm{H}_{2} \mathrm{~S}$-induced nasal injury [12]. Furthermore, physiological concentrations of $\mathrm{H}_{2} \mathrm{~S}$ could induce apoptosis of human periodontal ligament cells and human gingival fibroblasts in periodontitis, suggesting that $\mathrm{H}_{2} \mathrm{~S}$ may play an important role in periodontal tissue damage in periodontal diseases [13]. These findings suggest that $\mathrm{H}_{2} \mathrm{~S}$ causes upper respiratory tract epithelial damage that lead to bleeding from nose, pharynx, gum, tongue, trachea, and bronchi. The same mechanism may cause pharyngeal soreness, gingivitis, rhinitis, and eyes irritation. On chronic exposure, this also might cause gingival and periodontal disease among people who work in environment with presence of $\mathrm{H}_{2} \mathrm{~S}$. Acute, subchronic, and prolong exposure to $\mathrm{H}_{2} \mathrm{~S}$ might also cause neuronal olfactory damage, loss of smell sensation, and rhinitis which was reported in previous studies on human, rats, and mice $[4,7,14,15]$. At lower concentrations, $\mathrm{H}_{2} \mathrm{~S}$ was found to cause eye mucosal irritation, and keratoconjunctivitis called 'gas eye', and at higher concentrations there was risk of pulmonary edema [16]. There was evidence that chronic low-level exposure to $\mathrm{H}_{2} \mathrm{~S}$ might be associated with reduced lung function [17]. Lambert et al. (2006) reviewed several studies in regard to $\mathrm{H}_{2} \mathrm{~S}$ effect on eye. They concluded from some previous studies that acute $\mathrm{H}_{2} \mathrm{~S}$ exposure could produce eye irritation and toxic effects whereas with chronic exposure, serious eye effects were suggested [18]. Overproduction of endogenous $\mathrm{H}_{2} \mathrm{~S}$ was also found stimulating human aorta smooth muscle cells apoptosis [19]. An experimental study on mouse also revealed that the enzymes producing $\mathrm{H}_{2} \mathrm{~S}$ in lungs/ $\mathrm{H}_{2} \mathrm{~S}$ system play a critical protective role in the development of asthma [20]. A recent study in New Zealand provided no evidence that asthma risk increases with $\mathrm{H}_{2} \mathrm{~S}$ exposure. Suggestions of a reduced risk in the higher exposure areas are consistent with recent evidence that $\mathrm{H}_{2} \mathrm{~S}$ has signaling functions in the body, including induction of smooth muscle relaxation and reduction of inflammation [21]. This coincide with the findings in the present study in which there were no reported cases of asthmatic attack or exaggeration of pre-existent bronchial asthma upon $\mathrm{H}_{2} \mathrm{~S}$ exposure. A study on rat revealed a specific effect of inhalation natural $\mathrm{H}_{2} \mathrm{~S}$-containing gas on myelin sheaths in the brain, which determines its neurotoxicity even at low concentrations in the inspired air [22]. In human studies, it was concluded that neurophysiological abnormalities were associated with exposure to $\mathrm{H}_{2} \mathrm{~S}$ from crude oil among former workers and neighbors of a refinery [23]. Another study had investigated the cognitive functions among workers of sewer networks. It demonstrated that exposure to $\mathrm{H}_{2} \mathrm{~S}$ was associated with cognitive impairment [24]. However, in a community-based study on people with chronic exposure to $\mathrm{H}_{2} \mathrm{~S}$, the investigators revealed that deficits in overall neurobehavioral performance were not associated with such exposure [25].

The present study showed that nasal mucosa was the most profound respiratory site affected by $\mathrm{H}_{2} \mathrm{~S}$. This could be explained by fact that the nose is more vulnerable to the gas especially during sleep at night. It is the first part of respiratory passage for breathing process that exposed to the highest level of $\mathrm{H}_{2} \mathrm{~S}$ concentration. Thereafter $\mathrm{H}_{2} \mathrm{~S}$ might be reduced in concentration as it proceeds down into respiratory airways where the vast majority of $\mathrm{H}_{2} \mathrm{~S}$ is absorbed by nasal and sinuses mucosa. This finding is in 
concordance with that found in the animal studies in which they had shown that the nose was a particularly sensitive respiratory tract target for inhaled $\mathrm{H}_{2} \mathrm{~S}[26,27]$. The nasal cavity is lined with specialized epithelial cells that maintain the normal function of the nose. These surface epithelial cells have specific roles in conducting airflow and maintaining normal nasal function and include squamous, respiratory, transitional, and olfactory epithelium [28]. The vicinity of the respiratory and olfactory epithelial cells to inspired air makes them a target for cytotoxic damage [29]. Therefore, long-term exposure of low concentration of $\mathrm{H}_{2} \mathrm{~S}$ might cause loss of smell sensation.

The limitation of the present study is the small sample size because of the difficulty to confirm that $\mathrm{H}_{2} \mathrm{~S}$ was the culprit among several excluded cases. The study revealed subchronic $\mathrm{H}_{2} \mathrm{~S}$ effects on the upper respiratory system which had been rarely mentioned in the previous human studies. The prominent factor, which affects the health of oil field workers in regard to prolonged $\mathrm{H}_{2} \mathrm{~S}$ exposure, was the construction of the camp in the vicinity of oil wells and oil-separation stations. It is highly recommended to build workshops and living accommodation far away from these locations with especial emphasis on the dominant annual wind direction. The oil field camp should be constructed where the usual wind direction passes through camp first and then toward the oil wells and oil-separation stations. The waste water, which is separated from crude oil and expelled near the oil field camp, should be either injected into dead oil wells or throw far away from the camp. An advanced technological system could also reduce $\mathrm{H}_{2} \mathrm{~S}$ emission from its sources. In addition, automatic fire ignition devices for gas flares, which burn excess crude oil gas, should replace the old style manual fire ignition by pistol. The manual ignition was used at the oil fields during the period of the present study. These gas flares were extinguished spontaneously when there was reduction in pipe gas flow rate and/or high-speed wind. This led to high emission of $\mathrm{H}_{2} \mathrm{~S}$ whenever there was delay in manual ignition of the gas flares.

Reduction or disappearance of $\mathrm{H}_{2} \mathrm{~S}$ gas during midday period and summer season in the oil fields might be related to ultraviolet (UV) light destruction of the gas. This was confirmed experimentally in two previous studies. The photolysis was performed by applying UV light beam on $\mathrm{H}_{2} \mathrm{~S}$ gas inside pipe or container [30, 31]. The experiments revealed that UV light reduced $\mathrm{H}_{2} \mathrm{~S}$ concentration by photolysis or gas destruction. The level of $\mathrm{H}_{2} \mathrm{~S}$ photolysis was also related to several factors which included initial $\mathrm{H}_{2} \mathrm{~S}$ concentration, pipe diameter, ultraviolet light wavelength, relative humidity, and oxygen content. The highest activity for $\mathrm{H}_{2} \mathrm{~S}$ destruction was achieved with decreasing initial $\mathrm{H}_{2} \mathrm{~S}$ concentration, reduced pipe diameter, $80 \%$ relative humidity, and $21 \%$ oxygen content.

\section{Conclusion}

There was significant toxicant-induced damage of $\mathrm{H}_{2} \mathrm{~S}$ on the upper respiratory tract especially bleeding from several parts after subchronic exposure to low concentration of $\mathrm{H}_{2} \mathrm{~S}$. Few animal or human studies have mentioned subchronic health disturbances of low $\mathrm{H}_{2} \mathrm{~S}$ level. Long-term effects need to be evaluated especially in regard to periodontal disease. There should be discrimination between the health effects of high $\mathrm{H}_{2} \mathrm{~S}$ toxic level and lower concentration exposures. Larger studies upon several populations who live near low ambient concentration of $\mathrm{H}_{2} \mathrm{~S}$ might show some detrimental effects of such exposure. Reduction of ambient air $\mathrm{H}_{2} \mathrm{~S}$ level by sunlight was confirmed in the present study, but not reported in previous literature.

Conflict of interest The author declares that he has no conflict of interest.

\section{References}

1. Schroeter JD, Kimbell JS, Andersen ME, Dorman DC. Use of a pharmacokinetic-driven computational fluid dynamics model to predict nasal extraction of hydrogen sulfide in rats and humans. Toxicol Sci. 2006;94:359-67.

2. Shivanthan MC, Perera H, Jayasinghe $\mathrm{S}$, et al. Hydrogen sulphide inhalational toxicity at a petroleum refinery in Sri Lanka: a case series of seven survivors following an industrial accident and a brief review of medical literature. J Occup Med Toxicol. 2013;8:9.

3. Lindenmann J, Matzi V, Neuboeck N, et al. Severe hydrogen sulphide poisoning treated with 4-dimethylaminophenol and hyperbaric oxygen. Diving Hyperb Med. 2010;8:213-7.

4. Hirsch AR, Zavala G. Long term effects on the olfactory system of exposure to hydrogen sulfide. Occup Environ Med. 1999;56: 284-7.

5. Heaney CD, Wing S, Campbell RL, et al. Relation between malodor, ambient hydrogen sulfide, and health in a community bordering a landfill. Environ Res. 2011;111:847-52.

6. Lopez A, Prior M, Yong S, et al. Biochemical and cytologic alterations in the respiratory tract of rats exposed for 4 hours to hydrogen sulfide. Fundam Appl Toxicol. 1987;9(4):753-62.

7. Brenneman KA, Meleason DF, Sar M, et al. Olfactory mucosal necrosis in male $\mathrm{CD}$ rats following acute inhalation exposure to hydrogen sulfide: reversibility and the possible role of regional metabolism. Toxicol Pathol. 2002;30(2):200-8.

8. Hendrickson RG, Chang A, Hamilton RJ. Co-worker fatalities from hydrogen sulfide. Am J Ind Med. 2004;45:346-50.

9. Pearson RJ, Wilson T, Wang R. Endogenous hydrogen sulfide and the cardiovascular system-what's the smell all about? Clin Invest Med. 2006;29(3):146-50.

10. Wang R. Physiological implications of hydrogen sulfide: a whiff exploration that blossomed. Physiol Rev. 2012;92(2):791-896.

11. Ryazantseva NV, Novitsky VV, Starikova EG, et al. Role of hydrogen sulfide in the regulation of cell apoptosis. Bull Exp Biol Med. 2011;151(6):702-4.

12. Roberts ES, Wong VA, McManus BE, et al. Changes in intracellular $\mathrm{pH}$ play a secondary role in hydrogen sulfide-induced nasal cytotoxicity. Inhal Toxicol. 2006;18(3):159-67. 
13. Zhang JH, Dong Z, Chu L. Hydrogen sulfide induces apoptosis in human periodontium cells. J Periodontal Res. 2010;45(1):71-8.

14. Brenneman KA, James RA, Gross EA, et al. Olfactory neuron loss in adult male $\mathrm{CD}$ rats following subchronic inhalation exposure to hydrogen sulfide. Toxicol Pathol. 2000;28(2): 326-33.

15. Dorman DC, Struve MF, Gross EA, et al. Respiratory tract toxicity of inhaled hydrogen sulfide in Fischer-344 rats, SpragueDawley rats, and B6C3F1 mice following subchronic (90-day) exposure. Toxicol Appl Pharmacol. 2004;198(1):29-39.

16. Guidotti TL. Hydrogen sulphide. Occup Med (Lond). 1996;46(5): 367-71.

17. Richardson DB. Respiratory effects of chronic hydrogen sulfide exposure. Am J Ind Med. 1995;28(1):99-108.

18. Lambert TW, Goodwin VM, Stefani D, et al. Hydrogen sulfide $\left(\mathrm{H}_{2} \mathrm{~S}\right)$ and sour gas effects on the eye A historical perspective. Sci Total Environ. 2006;367(1):1-22.

19. Yang G, Wu L, Wang R. Pro-apoptotic effect of endogenous $\mathrm{H}_{2} \mathrm{~S}$ on human aorta smooth muscle cells. FASEB J. 2006;20(3): 553-5.

20. Zhang G, Wang P, Yang G, et al. The inhibitory role of hydrogen sulfide in airway hyperresponsiveness and inflammation in a mouse model of asthma. Am J Pathol. 2013;182:1188-95.

21. Bates MN, Garrett N, Crane J, Balmes JR. Associations of ambient hydrogen sulfide exposure with self-reported asthma and asthma symptoms. Environ Res. 2013;122:81-7.

22. Solnyshkova TG. Demyelination of nerve fibers in the central nervous system caused by chronic exposure to natural hydrogen sulfide-containing gas. Bull Exp Biol Med. 2003;136(4):328-32.
23. Kilburn KH, Warshaw RH. Hydrogen sulfide and reduced-sulfur gases adversely affect neurophysiological functions. Toxicol Ind Health. 1995;11(2):185-97.

24. Farahat SA, Kishk NA. Cognitive functions changes among Egyptian sewage network workers. Toxicol Ind Health. 2010;26 (4):229-38.

25. Inserra SG, Phifer BL, Anger WK, et al. Neurobehavioral evaluation for a community with chronic exposure to hydrogen sulfide gas. Environ Res. 2004;95(1):53-61.

26. Deng J-F. Hydrogen sulfide. In: Krieger GR, Sullivan JB, editors. Hazardous materials toxicology, clinical principles of environmental health. Baltimore: Williams \& Wilkins; 1992. p. 711-7.

27. ACGIH. TLVs and BEI. Threshold limit values for chemical substances and physical agents. Cincinnati: American Conference of Governmental Industrial Hygienists, Inc.; 1998.

28. Miller FJ. Nasal toxicity dosimetry of inhaled xenobiotics: implications for human health. Washington: Taylor \& Francis; 1995.

29. Shusterman D. Toxicology of nasal irritants. Curr Allergy Asthma Rep. 2003;3:258-65.

30. Xia LY, Gu DH, Tan J, et al. Photolysis of low concentration $\mathrm{H}_{2} \mathrm{~S}$ under UV/VUV irradiation emitted from microwave discharge electrodeless lamps. Chemosphere. 2008;71(9):1774-80.

31. Li X, Zhang G, Pan H. Experimental study on ozone photolytic and photocatalytic degradation of $\mathrm{H}_{2} \mathrm{~S}$ using continuous flow mode. J Hazard Mater. 2012;199-200:255-61. doi:10.1016/j. jhazmat.2011.11.006. 